\title{
WIZUALNOŚĆ GOOGLE SEARCH
}

\begin{abstract}
Kopeć Jarosław, Wizualność Google Search [The Visual Aspects of Google Search] edited by M. Krajewski - "Człowiek i Społeczeństwo”, vol. XXXVI, iss. 2, Poznań 2013, pp. 251-256. Adam Mickiewicz University Press. ISBN 978-83-232-2672-7. ISSN 0239-3271.

The article discusses the issue of colour-related metaphors used by institutions and common users for describing the experience of using the Web. The context of thinking about modern Internet in this text is provided by William Gibson's classic cyberpunk novel - Neuromancer. I assume that colours may be persuasive in presenting the Internet in specific, political and business-related context.

Jarosław Kopeć, Biblioteka Narodowa, Instytut Książki i Czytelnictwa, Pracownia Badań Czytelnictwa, al. Niepodległości 213, 02-086 Warszawa, Poland.
\end{abstract}

Z Internetu korzystamy prawie wszyscy, ale mało kto rozumie sposób jego działania. W takiej sytuacji dyskurs dotyczący Sieci opiera się w dużej mierze na metaforach. Metafory z kolei mają ladunek polityczny - sugerują interpretację zjawisk, których analizy nie jesteśmy w stanie przeprowadzić samodzielnie.

William Gibson, klasyczny twórca nurtu cyberpunk, odpowiedzialny między innymi za ukucie sformułowania "cyberprzestrzeń" 1 , w swojej pierwszej powieści Neuromancer ${ }^{2}$ (napisanej w 1984 roku) dostarcza metafor Sieci jako cyberprzestrzeni, która przypomina rzeczywistość właśnie w aspekcie przestrzenności, „terytorialności"3. Każdorazowo, gdy bohaterowie się w nią zanurzają, oglądają stereoskopowe obiekty, spirale, graniastosłupy, ostrosłupy, wszystkie w intensywnych kolorach. Zabezpieczenia

\footnotetext{
1 Termin cyberspace po raz pierwszy pada w jego opowiadaniu Burning Chrome zamieszczonym w magazynie „Omni” w 1981 roku.

2 W. Gibson, Neuromancer, Warszawa 1992.

3 Tego terminu używa Gibson w filmowym wywiadzie No Map for These Territories, reż. M. Neale, 2000.
} 
antywłamaniowe nazywane są "Lodem"4. Przełamywanie Lodu, a więc łamanie zabezpieczenia komputerowego, przypomina wciskanie w szczelinę skały pnia ściętego drzewa, by napęczniał pod wpływem wody i rozsadził kamień. Ta nazwa konotuje związek Sieci z naturą. Interesująca jest zarazem opozycja pojęciowa wobec znacznie częściej używanego do nazywania takiego oprogramowania w rzeczywistości słowa "firewall” („zapora ogniowa"). Do opisu tego samego zjawiska używane są dwie ekstremalne metafory nawiązujące do żywiołów: ognia i lodu.

Osiowym bohaterem powieści jest Wintermute - sztuczna inteligencja, która pragnie połączyć się ze swoim „bratem” - Neuromancerem. Owocem ich fuzji ma być samodzielna, samoświadoma i rozwijająca się sztuczna inteligencja. Sytuacja przypomina tę ze Slapstick albo nigdy więcej samotności ${ }^{5}$ Kurta Vonneguta, gdzie dwójka rodzeństwa osiąga pełnię możliwości intelektualnych dopiero wówczas, gdy są blisko siebie. Oboje uosabiają przy tym różne aspekty inteligencji - charakteryzującą lewą półkulę mózgu racjonalność i skojarzoną z połową prawą kreatywność.

W Neuromancerze zatem Sieć jest z jednej strony sztuczną kopią natury, z jej przestrzennością i nawiązującymi do natury metaforami, z drugiej bohaterowie obawiają się przekroczenia przez program (sztuczny) podległości wobec człowieka (natury). Przerażające dla bohaterów są te momenty, kiedy Wintermute interweniuje $\mathrm{w}$ świat materialny, przekraczając tę granicę.

Osobami, które w powieści Gibsona mają dostęp do Sieci, są specjaliści, profesjonaliści. Podobnie jest $\mathrm{w}$ Matriksié $^{6}$. Tam ciągi zielonych znaków spadających po czarnym ekranie monitora są zrozumiałe tylko dla przygotowanych użytkowników/hackerów, którzy zrozumieją tytułową metaforę Sieci - matrycę.

Sally $\mathrm{Wyatt}^{7}$ analizuje metafory wykorzystywane w dyskursie współczesnych webentuzjastów na przykładzie publicystów „Wired" 8 . Określa ich mianem dynamistów - osób pozytywnie reagujących na postęp informatyzacji, przeważnie libertarian sprzeciwiających się biurokracji. Dynamiści używają w odniesieniu do Sieci metafor organicznych - ewolucji, rozwo-

\footnotetext{
${ }^{4}$ Oryginalnie anglojęzyczny skrótowiec „ICE” od „Intrusion Countermeasures Electronics”. Termin stosowany też $\mathrm{w}$ odniesieniu do faktycznie produkowanego oprogramowania antywłamaniowego. Tłumacz polskiego wydania zdecydował się jednak spolszczyć nazwę i zachować skojarzenie z lodem.

${ }^{5}$ K. Vonnegut, Slapstick albo nigdy więcej samotności, Warszawa 2004.

${ }^{6}$ The Matrix, reż. A. i L. Wachowski, 1999.

${ }^{7}$ S. Wyatt, Danger! Metaphors at Work in Economics, Geophysiology, and the Internet, "Science, Technology, \& Human Values" 2004, vol. 29. Artykuł rozwija też wątek metafor służących opisywaniu Internetu jako polityki.

${ }^{8}$ Dystrybuowany w wersji papierowej i on-line pod adresem http://wired.com.
} 
ju, wzrostu, działania. Wyatt przeciwstawia im polityków-technokratów, którzy sięgają raczej po terminy związane z szybkim przemieszczaniem się informacji, np. „infostrada”. Publicyści „Wired” są więc według jej diagnozy przeciwnikami instytucjonalizacji Sieci, choć zdają się zapominać o instytucjonalnych początkach Internetu.

Sposób generowania wyników przez wyszukiwarki Google w ostatnim czasie przeszedł znaczącą zmianę, na której nie chcę się w tym artykule koncentrować. Wystarczy powiedzieć, że algorytm przeszedł od arbitralności instytucjonalnej ${ }^{9}$ do arbitralności społecznościowej ${ }^{10}$. Chcę natomiast przeanalizować wizualność i metaforyczny język wyszukiwarek Google pod kątem ich polityczności. Moim naczelnym celem jest wskazanie na te aspekty Sieci jako znaczące.

Strona główna wyszukiwarki Google zmieniała się na przestrzeni czasu11, zachowując jednak swoje podstawowe charakterystyki. Wersja z 1997 roku miała białe tło, logo w tych samych kolorach co współcześnie, tylko zapisane grubszym krojem. W roku 2006 pojawiło się na niej coś, co ciąży na współczesnym nie tylko wizerunku, ale i sposobie działania Google górny pasek służący do obsługi indywidualnego konta użytkownika. Aktualny ${ }^{12}$ wygląd głównej strony pochodzi z roku 2011, kiedy pasek społecznościowy (zawierający już linki do większej liczby aplikacji Google) odcięto wyraźną ciemną szarością, a po prawej stronie pojawiły się ikony Google+ (serwisu społecznościowego).

Strona z wynikami również zmieniała się nieznacznie. Najnowszym elementem jest dziś wyświetlanie rezultatów jeszcze w trakcie wpisywania przez użytkownika swojego zapytania i generowanie podpowiedzi - uzupełnianie tekstu wpisywanego przez użytkownika, zanim postawi ostatnią literę. Tę opcję można wyłączyć w panelu ustawień.

Już na pierwszy rzut oka widać, że wizualność strony Google dalece odbiega od estetyk, o których pisał Gibson albo którą widzieliśmy w Matriksie. Kolorystyką współczesnej Sieci jest triada biały-czarny-niebieski. Wystarczy spojrzeć choćby na Facebooka, Wikipedię, witryny Apple. Błękit konotuje nowoczesność, technologię, czystość, biel z kolei transparentność. Niebieski nawiązuje zarazem do początków WWW - kiedy w języku

\footnotetext{
${ }^{9}$ Wyniki wyszukiwania generowane były na podstawie algorytmu PageRank hierarchizującego strony według liczby i wartości linków, które do niej prowadziły z innych witryn.

10 Wyniki wyszukiwania generowane są przy filtrowaniu przez indywidualne preferencje wyszukującego. Filtry powstają na bazie historii wyszukiwań i danych z serwisów spolecznościowych, a więc biorą pod uwagę zainteresowania, poglądy i doświadczenia nasze i naszych znajomych.

${ }^{11}$ Archiwum zrzutów ekranu strony głównej Google znaleźć można na stronie „Blogscoped": http:// blogoscoped.com/archive/2006-04-21-n63.html [dostęp: 14.06.2012].

12 Stan na marzec 2012.
} 
HTML zapiszemy link, ale nie określimy specjalnie jego koloru, w przeglądarce internetowej będzie on wyświetlany $\mathrm{w}$ tym właśnie kolorze. Tło wyszukiwarki jest białe jak kartka papieru. Google, komunikując się z użytkownikami za pośrednictwem swojego bloga, określa wyniki wyszukiwania pozycjonowane według algorytmu, niesponsorowane, mianem „organicznych"13.

Strony internetowego wydania magazynu "Wired" również utrzymane są $\mathrm{w}$ trójce kolorów: czerń, biel, błękit. Zieleń, którą pamiętamy z Matriksa, znane z Neuromancera ostro odcinające się na tle czarnej próżni jaskrawa biel, fiolety i czerwienie, kojarzące się z miastem neonów (Gibson sięga po metaforę miasta $\left.{ }^{14}\right)$, odeszły w niepamięć.

Wojciech Orliński w pierwszej notce na swoim blogu, którego szata graficzna utrzymana jest w czerni, bladej zieleni i bieli, pisze:

„POKE 53280,0:POKE 53281,0. Kiedyś od takich dwóch poleceń zaczynałem każdy kontakt z komputerem. Commodore 64 domyślnie odpalał się w niewygodnym zestawie kolorów (jasnoniebieska ramka, ciemnoniebieskie tło, jasnoniebieskie literki). Tło i ramkę zmieniałem na czarne, a kolor literek na zielony, bo wtedy podłączony do telewizora komodorek wyglądał trochę bardziej jak terminal znakowy u ojca w pracy..." 15 .

Czerń i zieleń są dla dziennikarza kolorami komputera ekskluzywnego, dostępnego tylko dla inżynierów-specjalistów, bez lekkości białego tła i odcinającego się na jego tle jak czcionka drukarska czarnego tekstu.

W 1997 roku witryna wyszukiwarek Google i Yahoo odróżniała się swoją estetyką na tle przeładowanej kolorami i niskiej jakości grafikami reszty Sieci. Z czasem wiele firm weszło na ścieżkę minimalizmu. Wystarczy porównać wygląd strony głównej AOL.com z lat 199616 i $2012^{17}$.

Ta zmiana w Sieci miała związek z popularyzacją dostępu do WWW. Ciemne tła i kontrastujące barwy neonów sprawiały wrażenie, że Internet jest przestrzenią mroczną, dostępną tylko dla wprawionych użytkowników. Stąd romantyczny mit hackera jako podróżnika po nieznanym, wędrowca rubieży cywilizacji. I stąd być może także dzisiejsze zjawisko archeologii

${ }^{13} \mathrm{~W}$ odróżnieniu od wyników reklamowych, za których umieszczenie na stronie z wynikami wyszukiwania Google pobiera opłaty - te widzimy przede wszystkim w prawym górnym rogu ekranu wyników wyszukiwania. Patrz: J. Battelle, Szukaj. Jak Google i konkurencja wywotali biznesowa i kulturowa rewolucje, Warszawa 2006.

${ }^{14}$ No Map for These Territories, op. cit.

${ }_{15}$ W. Orliński, Zielono na czarnym, http://wo.blox.pl/2006/08/Zielono-na-czarnym.html [dostęp: 14.06.2012].

16 Squareoak.com, http:/ / www.squareoak.com/blog/the-internet-of-1996-1997-a-waybacktour-pics/ [dostęp: 14.06.2012].

17 http:/ / aol.com [dostęp: 14.06.2012]. 
Internetu - odzyskiwania materiałów zamierzchłej Sieci. Interesującej parodii tego ewenementu dostarczyli twórcy serwisu "TheOnion.com" publikującego dowcipne udawane materiały telewizyjne na wzbogacone wyobraźnią, ale zakorzenione w rzeczywistości tematy. Internet Archeologists Find Ruins of Friendster Civilization ${ }^{18}$ (Archeolodzy Internetu odnaleźli ruiny cywilizacji Friendster ${ }^{19}$ ), podał serwis. W materiale filmowym dziennikarze przypominający prezenterów telewizji śniadaniowej rozmawiają z mężczyzną wyglądającym na archeologa pracującego w Afryce, który dokonał przełomowego odkrycia dzięki przeglądarce na swoim komputerze. Mówią o Friendsterze, serwisie społecznościowym „opuszczonym przynajmniej od roku 2005 po Chrystusie". Te pierwsze przebłyski nowej sieci 2.0, opartej na partycypacji użytkowników, są dla współczesnego Internetu czymś jak antyk czy inna przełomowa epoka dla kultury XXI wieku. Stąd gdy dziennikarka mówi z podnieceniem: „możemy się tak wiele nauczyć z ruin tego miejsca", w tej grubymi nićmi szytej parodii może być ziarnko prawdy.

Minimalizm przeglądarki Google jest zwodniczy w tym sensie, że użytkownik odnosi wrażenie obcowania z medium, trzymając się typologii Marshalla McLuhana, „chłodnym”. Wydaje się, że to coś przypominającego biblioteczny katalog, gdzie bibliotekarz nie ingeruje w wyniki naszych poszukiwań. Ale na każdym etapie działania Google, począwszy od czasów PageRanka, po współczesny model społecznościowy, algorytm firmy ingerował $\mathrm{w}$ wyniki bardzo mocno poprzez ich hierarchizowanie i filtrowanie, dostarczając przy tym "gorącego" poczucia wszechogarnialności listy wyników.

Najbardziej oczywistym z filtrów jest filtr rodzicielski, który ma strzec dzieci przed dostępem do stron dla nich nieodpowiednich. Ale ten filtr rodzic może włączać i wyłączać. Inne filtry są mniej widoczne. Dotyczą dostosowywania treści do naszego miejsca podłączenia do Sieci, a także danych, które Google zbiera na nasz temat $\mathrm{w}$ historii wyszukiwania i serwisach społecznościowych. Wnioskować na temat działania tych filtrów możemy tylko na podstawie obserwacji i porównywania, bo dokładne algorytmy firmy są tajne. Zagadnienie to $\mathrm{w}$ najbardziej zwięzły i metodyczny sposób przedstawia Eli Parisier w swoim wystąpieniu podczas konferencji TED20, podczas którego przestrzega słuchaczy przed „filtrowymi bąblami”. Skutkiem nowej polityki Google jest zamykanie użytkowników w informacyjnym

\footnotetext{
$18 \mathrm{http}$ // www.theonion.com/video/internet-archaeologists-find-ruins-of-friendster-c,14389/ [dostęp: 14.06.2012].

19 Przekład J.K.

${ }^{20}$ E. Parisier, Beware online "filter bubbles", http://www.ted.com/talks/eli_pariser_bew are_online_filter_bubbles.html [dostęp: 14.06.2012].
} 
więzieniu ich zainteresowań i poglądów. Mamy coraz mniejsze szanse trafić poprzez wyszukiwarkę na zagadnienia, które dotychczas interesowały nas mało, na poglądy, które są odmienne od naszych, czy na rzeczy, które nie dotyczą nas bezpośrednio.

Parisier cytuje Marka Zuckerberga, twórcę i dyrektora Facebooka: „Wiewiórka umierająca przed twoim domem może bardziej pasować do twoich zainteresowań niż ludzie umierający w Afryce"21.

Neutralna wizualność Google zdaje się podtrzymywać pozory obiektywizmu działania algorytmu i "chłodności” medium, które czeka na użytkownika, by wypełnił je interpretacjami. Tymczasem liczba wyników, które Google podaje w odpowiedzi na nasze zapytania, jest tak ogromna, że stwarza wrażenie obejmowania całości Internetu. I wówczas strona Google staje się "gorąca", idąc za typologią McLuhana.

W kontaktach z dziennikarzami pracownicy korporacji, kiedy zarzuca im się ingerowanie $\mathrm{w}$ wyniki, odpowiadają zawsze, że zabiegi te mają na celu poprawę jakości wyszukiwania ${ }^{22}$. Podtrzymują zatem wizję technokratycznego doskonalenia, zbywając zarzuty o formowanie społeczeństwa źle rozumianych zamkniętych kręgów towarzyskich, o powrót do społeczeństwa wspólnot opisanych przez Zygmunta Baumana ${ }^{23}$ jako grup, które dla swojego istnienia muszą być częściowo odcięte od świata, gdyż inaczej mogłyby upaść aksjomaty, na których zostały ufundowane.

\section{BIBLIOGRAFIA}

Battelle J., Szukaj. Jak Google i konkurencja wywołali biznesowa i kulturowa rewolucje, Warszawa 2006

Bauman Z., Wspólnota, Kraków 2008.

Blogscoped, Google.com 1997-2011, http://blogoscoped.com/archive/2006-04-21-n63. html [dostęp: 14.06.2012].

Gibson W., Neuromancer, Warszawa 1992.

Orliński W., Zielono na czarnym, http://wo.blox.pl/2006/08/Zielono-na-czarnym.html [dostęp: 14.06.2012].

Parisier E., Beware online "filter bubbles", http://www.ted.com/talks/eli_pariser_beware_ online_filter_bubbles.html [dostęp: 14.06.2012].

Vonnegut K., Slapstick albo nigdy więcej samotności, Warszawa 2004.

Wyatt S., Danger! Metaphors at Work in Economics, Geophysiology, and the Internet, "Science, Technology, \& Human Values" 2004, vol. 29.

No Map for these Territories (film dokumentalny), reż. M. Neale, 2000.

The Matrix (film fabularny), reż. A. i L. Wachowski, 1999.

\footnotetext{
${ }^{21}$ Przekład J.K.

$22 \mathrm{~J}$. Battelle, op. cit.

${ }^{23}$ Z. Bauman, Wspólnota, Kraków 2008.
} 